\title{
Design and Build a Camera Directional Movement Control Device based on Sound Source Position Detection
}

\author{
Ahmad Syarif Hidayat \\ Electrical Engineering Master Program, \\ Gunadarma University, \\ JI. Margonda Raya 100, Depok, West Java 16424, \\ Indonesia
}

\author{
Wahyu Kusuma Raharja \\ Electrical Engineering Master Program, \\ Gunadarma University, \\ Jl. Margonda Raya 100, Depok, West Java 16424, \\ Indonesia
}

\begin{abstract}
Webcam or web camera may be a computerized medium utilized for computers or portable workstations. Webcams work to capture pictures specifically, particularly amid gatherings and online instructing and learning forms that require face-to-face gatherings. The face-to-face assembly points to decide whether specialists and teachers are in a position and go to gatherings and the instructing and learning prepare well. However, the camera capture does not point to the user's confront and manually sets in its application. One way to overcome this is often by utilizing confront location and creating by taking after the position of the confront by utilizing confront following. The presence of Confront Following permits the capture of a confront concurring to the identified user is confronted so that it does not get to physically sets. So it is essential to plan an instrument that controls the development of the camera heading. The comes about of this consider are anticipated to assist with the issue of utilizing assembly determination cameras on Raspberry Pi devices and utilizing sensor sound to identify the nearness of assembly camera clients. The result is the utilization of 2 sound sensors to identify the nearness of the client, and the camera turns 180 degrees with a sound intensity of $74 \mathrm{~dB}$. The most excellent determination was gotten to induce the quality of utilizing confront following where the test was carried out at a determination of $160 \times 128,320 \times 480$, and $640 \times 480$ and got the finest comes about with a determination of $640 \times 480$ with a most significant confront discovery separate of 8 meters, and a determination of 160x128 getting the least comes about with a confront location of 1 meter.
\end{abstract}

\section{Keywords}

Face Tracking, Raspberry Pi, RaspiCam, Python, OpenCV.

\section{INTRODUCTION}

Covid-19 could be a pandemic that stresses numerous individuals since the infection is straightforward to spread rapidly. This infection can assault anybody who has coordinated physical contact with those contaminated with the infection in social organizing. One of the numerous nations influenced by this widespread in Indonesia. Hence, the government quickly made a few arrangements that must be complied with the community to break the chain of the Covid19 infection, one of which was by executing learning and working from domestic that taken after mechanical improvements - the alteration of data and communication technology, particularly within computerized interaction between instructors and understudies.
Minister of Education and Culture (Mendikbud) [6] Nadiem Anwar Makarim guarantees that the learning from the domestic approach is appropriatelyexecuted. The Minister of Education and Culture also took the activity to assist overcome impediments confronted by instructors, guardians, and understudies amid online learning, such as providing web get to within the shape of considering standards.

Laborers can still hold gatherings, and instruction performing artists can carry out online instructing and learning utilizing applications such as Google Classroom, E-learning, Zoom gatherings, Google Meet, and other stages to extend efficiency. In expansion, there are still numerous supporting media to meet the online needs of each understudy, workers who work from domestic (work from home), one of the foremost vital supporters may be a web camera (Webcam).

A webcam or camera could be a computerized media associated with a computer or portable workstation through a remote organization or associated employing a USB cable. Webcams work to capture pictures straightforwardly, particularly amid gatherings and online instructing and learning forms that require face-to-face gatherings. Face-toface points to discover whether specialists and instruction onscreen characters are in their position and go to gatherings and educate and learn. Be that as it may, in its application, the camera capture position does not point to the user's confront and must be set physically.

One way to overcome this is often by utilizing confront location and creating by taking after the position of the confront by utilizing confront following. The presence of Confront Following permits the confrontation capture position according to the detected user is confronted, so there is no ought to set it physically. There are numerous sorts of inquire about on following targets or objects. For case, Bo Zhang, Jun Haung, and Jinlong Lin [1] proposed a modern PID calculation for the following objects. Based on the foundation that has been expressed, the creator is inquisitive about building an apparatus, specifically the Design and Build a Camera Directional Movement Control Device Based on Sound Source Position Detection.

\section{LITERATURE REVIEW}

\subsection{Computer Vision}

Computer Vision could be a preparation of changing or changing information from video cameras or photos/images into a new choice or introduction, where the comes about of the change have an intrigued in accomplishing an objective. 
The information entered into the change movement makes it conceivable to have relevant data, such as a photo/image with different objects.In this way, choices will be made on the picture, for illustration within the shape of "what is the person's confront within the picture?" or "Who are the individuals within the photo?". The changes to an unused presentation include changing the picture to grayscale or cutting objects within the picture.

Not at all like the case with people who have contemplations to investigate, get it, and compare data on objects straightforwardly with data from encounters picked up amid a long time of living within the world. In a machine vision framework, computers can get data within the frame of a collection of numbers from information input media such as cameras or diskettes.

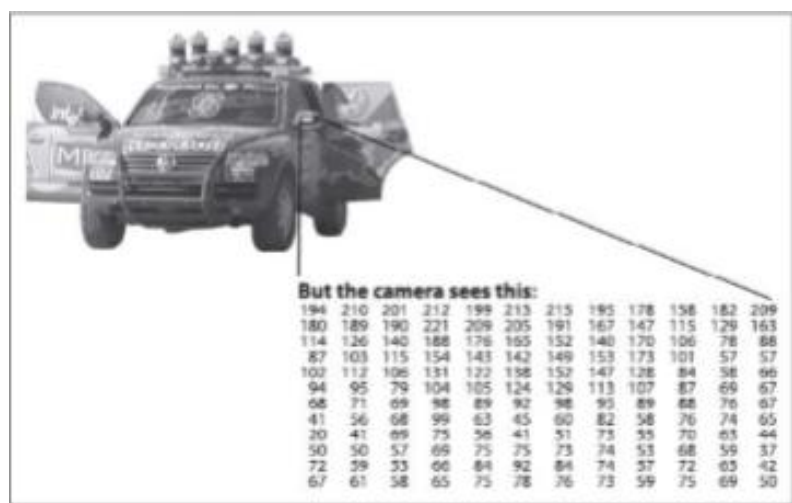

Fig 1: Computer Vision Overview [4]

Figure 1 acknowledges that the side reflected within the car picture is fair to a collection of numbers when seen by a computer. Of course, these numbers still have a parcel of clamor or obstructions so that the data contained is minimal. Usually, since computer vision is constrained to as it were two measurements (2D) but the objects handled are genuine world 3-dimensional (3D) objects, the data gotten encounters a part of unsettling influences and deterrents from different wonders in real life (climate, light, shadows)., light reflection, and development). In this way, it gets to be an issue that's continually being investigated to discover ways or procedures for tackling it [4].

\subsection{Haar Algorithm Working System}

The Haar calculation employments measurable strategies to perform eye acknowledgment. This strategy employments straightforward haar-like highlights as well as a cascade of boosted tree classifiers [7]. This classifier employments fixedsized pictures. The workings of the Haar in identifying the eye is to utilize a sliding window method on the whole image and seek whether there is a portion of the picture that's molded like an eye or not. Haar moreover can perform scaling to identify the nearness of eyes that are bigger or littler than the picture within the classifier.

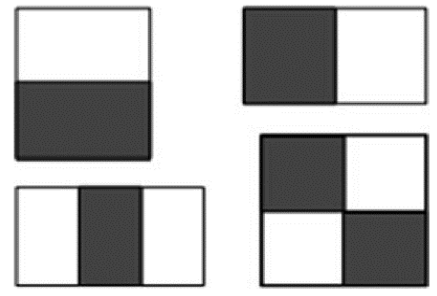

Fig 2: Haar Feature [10].
The most significant advantage of a highlight like Haar over most others is its computational speed. Due to the utilization of whole pictures, Haar-like highlights of any estimate can be computed in steady time (around 60 chip informational for a 2-rectangular include).

\subsection{Raspberry Pi}

Raspberry Pi may be a single-board computer arrangement created within the UK by the Raspberry Pi Establishment to present essential computer science to schools to deliver a modern era of programming as composed on the Raspberry Pi Foundation's official site. Nevertheless, in its advancement, the Raspberry Pi became more prevalent than expected and picked up excitement past its deals targets for case utilizes within the field of mechanical autonomy.

Raspberry Pi has discharged a few eras of its three models, to be specific the Pi Zero, Demonstrate A and Demonstrate B. All of these Raspberry models actualize a Framework on Chip (SoC) [9], Broadcom which is coordinates with the CPU and GPU on -ARM consistent board.

Until presently, the advancement of the Raspberry Pi form has come to a few eras, and indeed in June 2019, the Raspberry Pi Establishment authoritatively presented the most recent form of their mini-PC variation, the Raspberry $\mathrm{Pi} 4$. Of course, this news brings new to discuss to engineers, since Raspberry Pi 4 has a few equipment changes that can indeed be said to be one of a kind, such as the utilize of USB sort C, CPU ARM Cortex-A72 1.5 GHz quad-core 64-bit, which is claimed to have three times superior execution than its forerunner adaptation, full-throughput gigabit ethernet, Bluetooth. 5.0, double screen bolster through the micro-HDMI harbor, $4 \mathrm{~K}$ video decoder, and accessible in a few Smash capacity alternatives extending from $1 \mathrm{~GB}, 2 \mathrm{~GB}$, and $4 \mathrm{~GB}$.

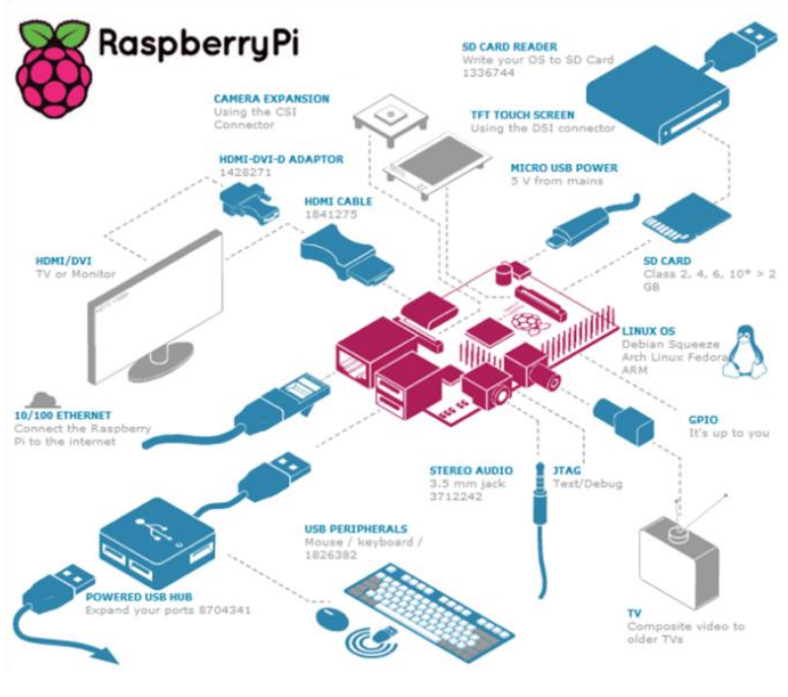

Fig 3: Raspberry Pi

\subsection{Servo Motor}

Servo enginescan work in two headings, and servo engines work with a closed criticism framework where the position of the servo engine will be educated back to the control circuit within the servo engine. The servo engine comprises an engine, an adapt circuit, a potentiometer, and a control circuit. The potentiometer on the servo engine capacities is a determinant of the point restrain of the servo revolution [13]. Servo engines more often than not as they were moved to a certain point and not ceaselessly. In any case, for a few purposes, the servo engine can be altered to move 
persistently.Taking after are the determinations of the servo motor:

1. Has three lines of power, ground, and control cables

2. The control signal controls the position

3. A pulse width of $20 \mathrm{~ms}$ controls the operation of the servo motor

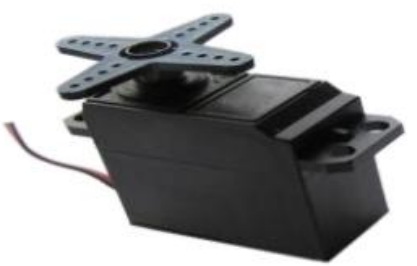

Fig 4: Servo Motor [13]

\subsection{Sound Sensor KY-037}

Sound Sensor KY-037 The sound sensor works based on the measure of the sound wave quality hitting the sensor layer, which causes the sensor layer to move, incorporating a tiny coil behind the layer up and down. The details of this sensor are source voltage $3.3 \mathrm{~V}$ to $5 \mathrm{~V}$, and the work is to identify sound concentrated rapidly, analog interface, and measure 22 x $32 \mathrm{~mm}$ (0.87 x 1.26 inches) [2].

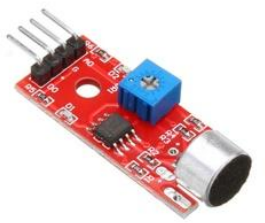

Fig 5: Sound Sensor KY-037 [2]

\section{RESEARCH METHODS}

\subsection{System Design}

Within the framework plan, there is a camera input that functions for the Webcam, which could be a fringe within the frame of a camera as an image/picture taker and two sound locators as a sound/audio collector which is controlled by a minicomputer (Raspberry Pi) or by a computer organize. A webcam can be built as a security framework with spilling video to screen in real-time.

This confronts the following framework has three yields, Screen, Servo Pan-Tilt Hat, and Speaker. The screen acts as an instrument to show data from handling minicomputer devices utilizing cable media or being controlled remotely (farther). The Servo Pan Tilt Hat functions as a motor component that supports face tracking that helps the camera determine the direction of the up, down, left, and correct positions.

This framework uses a Raspberry Pi 4 microcontroller as a centralized control unit and minicomputer. Raspberry will handle and run the OpenCV program, and after that, it will send information to the actuator in agreement with the program rules outlined within the Design and Build a Camera Directional Movement Control Device Based on Sound Source Position Detection.

The physical usage of the Plan and Construct of Camera Directional Development Control Devices Based on Detection of the Position of the Sound Source as appeared in Figure 6.

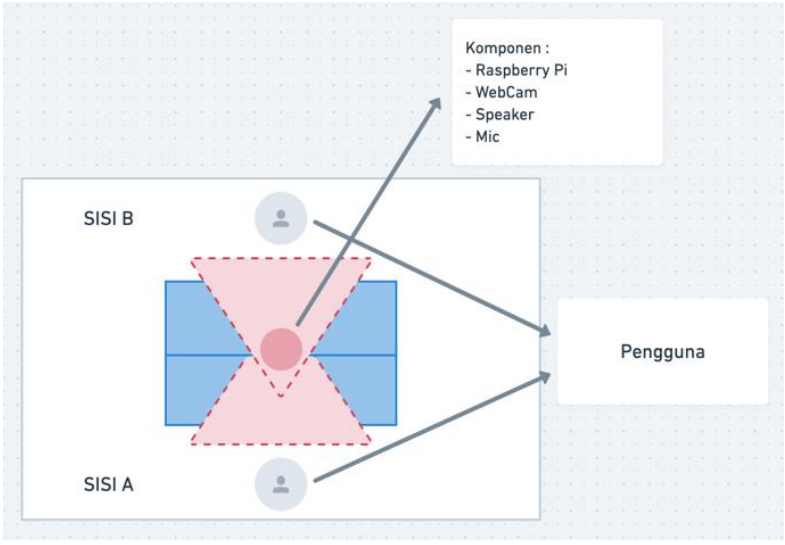

Fig 6: Webcam Position Overview

\subsubsection{Design Dimensions Size}

When the component installation has been carried out, the measurements of the plan are created, the taking after sizes are:

1. Design length $: 18 \mathrm{~cm}$.

2. Width of design $: 12 \mathrm{~cm}$.

3. Design height $: 14 \mathrm{~cm}$.

4. Design volume $: 3024 \mathrm{~cm}^{3}$.

\subsubsection{Material Structure Design of Face Tracking} System

1. Design Section
a. 3D Print servo Pan Tilt Hat

b. Raspberry Pi box

2. Electronics Section
a. $\quad 1 \mathrm{pc}$ Raspberry $\mathrm{Pi}$
b. $1 \mathrm{pc}$ Raspberry Camera
c. 3pcs Servo Motors
d. 1pc PCA9685 Servo module
e. 2pcs Sound Sensor KY-038
f. $1 \mathrm{pc}$ Monitor

\subsection{Hardware Design}

Making a hardware system is the arrangement of making a circuit that's utilized within the fabricate of a camera direction development controller based on the discovery of the position of the sound source.

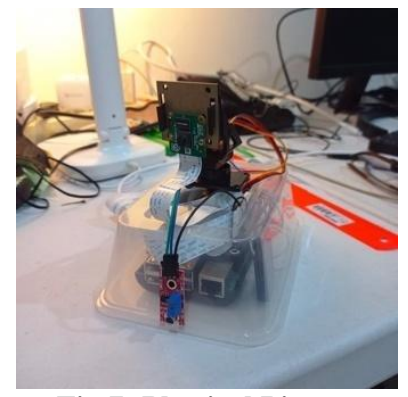

Fig 7: Physical Picture

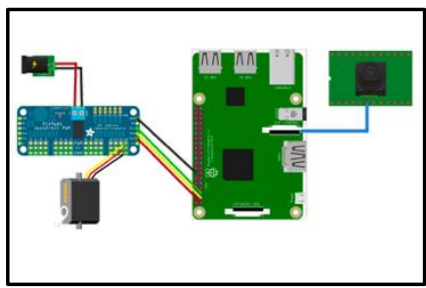

Fig 8: Hardware Connection Diagram 
Figure 8 may be a connection diagram on the Raspberry Pi, and the Raspberry Pi over gets input from the camera through the camera port accessible on the Raspberry Pi. At that point, the Servo Motor is connected to the Servo Driver. After that, the excellent discovery is associated with the Raspberry Pi. For communication with the wifi, which is now implanted within the Raspberry $\mathrm{Pi}$, is utilized for web organize associations.

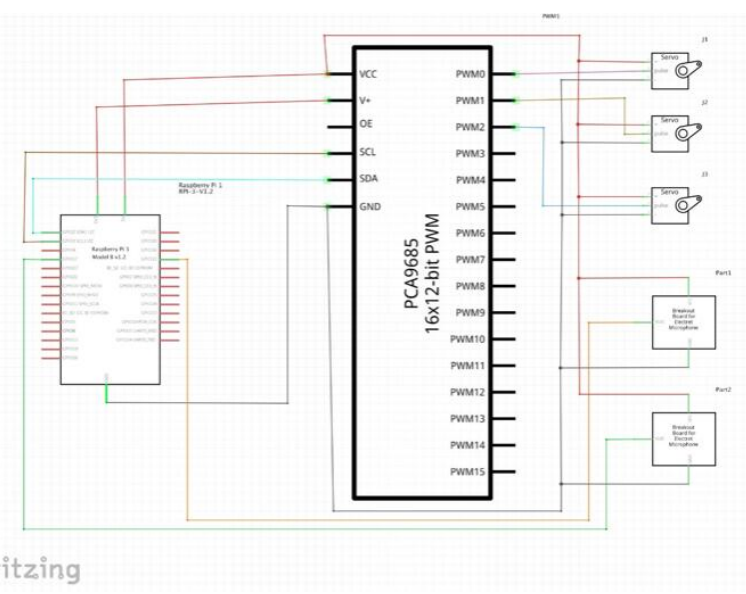

Fig 9: Circuit Schematic

Figure 9 could be an arrangement of confrontingthe following cameras based on raspberry pi, where the raspberry camera is associated with the CSI port on the raspberry pi board employing a flexible cable. At that point, the servo motor component is associated with the PCA9685 engine driver module, and there is a $\mathrm{V}+$ control cable, PWM cable for servo tweak, and GND. At that point, the PCA9685 engine driveris associated with raspberry pi, and there are control cables $\mathrm{V}+$, VCC control, GND, and SDA SCL ports as I2C communication for multi-servo utilize on the PCA9685 engine driver.

Table 1. Input and Output Data on Raspberry Pi

\begin{tabular}{|c|c|c|}
\hline PIN GPIO & TYPE & COMPONENT \\
\hline PI 3V3 & Output & VCC PCA9685 \\
\hline PI GND & Output & GND PCA9865 \\
\hline PI SCL & Output & SCL PCA9865 \\
\hline PI SDA & Output & SCA PCA9865 \\
\hline PWM PCA9685 & Output & $\begin{array}{c}\text { Servo Orange } \\
\text { Wire }\end{array}$ \\
\hline V+ PCA9685 & Output & Servo Red Wire \\
\hline GND PCA9865 & Output & Servo Brown Wire \\
\hline CSI PORT & Input & Pi Camera \\
\hline GPIO17 & Input & Sound Detection 1 \\
\hline GPIO18 & Input & Sound Detection 2 \\
\hline
\end{tabular}

In agreement with Table 1, there is input and yield information on the components introduced on the raspberry pi. The control and ground of the three servo engines come from $5 \mathrm{~V}$ ground, the PWM servo engine is associated with the PCA9685 driver stick, and the sound discovery KY-038 is associated with the Raspberry Pi through the GPIO17 and GPIO18 ports. After all, components are introduced accurately, and the following step is to plan the program or computer program required by the raspberry pi.

\subsection{Software Design}

Programming calculation may be a way to clarify the steps of a program or framework execution. One way to clarify how the stream of a framework or program runs is to utilize a flowchart.

Based on Figure 10, the flowchart graph of the Design and Build a Camera Directional Movement Control Device Based on Sound Source Position Detectionis partitioned into a few steps, specifically as follows:

1. The first step of the device framework begins with a beginning image demonstrating that the program is around to begin.

2. The second step of the tool runs the initialization command for the components that have been associated and alters the servo position at a foreordained position.

3. The third step is the program gives the command to make a frame that's utilized as a virtual camera concurring to the program code that's made, which is $320 \times 240$ pixels in the measure.

4. In the Fourth step, there are two sound sensors, sound sensor one will point the camera to the north side, and sound sensor 2 focuses the camera to the south side.

5. In the fifth step, when the camera identifies a confrontation, the program will study the facilitates of the identified confrontation.

6. Sixth step, whether the confront is within the center position of the outline or not, on the off chance that not, it will once more calculate the offset percentage on the recognized confront, at that point it will be executed to the actuator (servo pan-tilt hat) to form developments concurring to the counterbalanced calculation within the program and return to fourth arrange.

\section{RESULT AND DISCUSSION}

The comes about gotten in this study could be a face-tracking camera assembly with the confront the following strategy. This camera can take after objects within the user's frame areconfronted well based on the sound source.

In this chapter, a few tests are carried out in understanding with the investigation conducted, including:

1. Testing The appearance of a green square on the face

2. Face tracking distance test based on video resolution

3. Video offset distance test on face tracking response

4. Sound detection test against Camera Movement. 


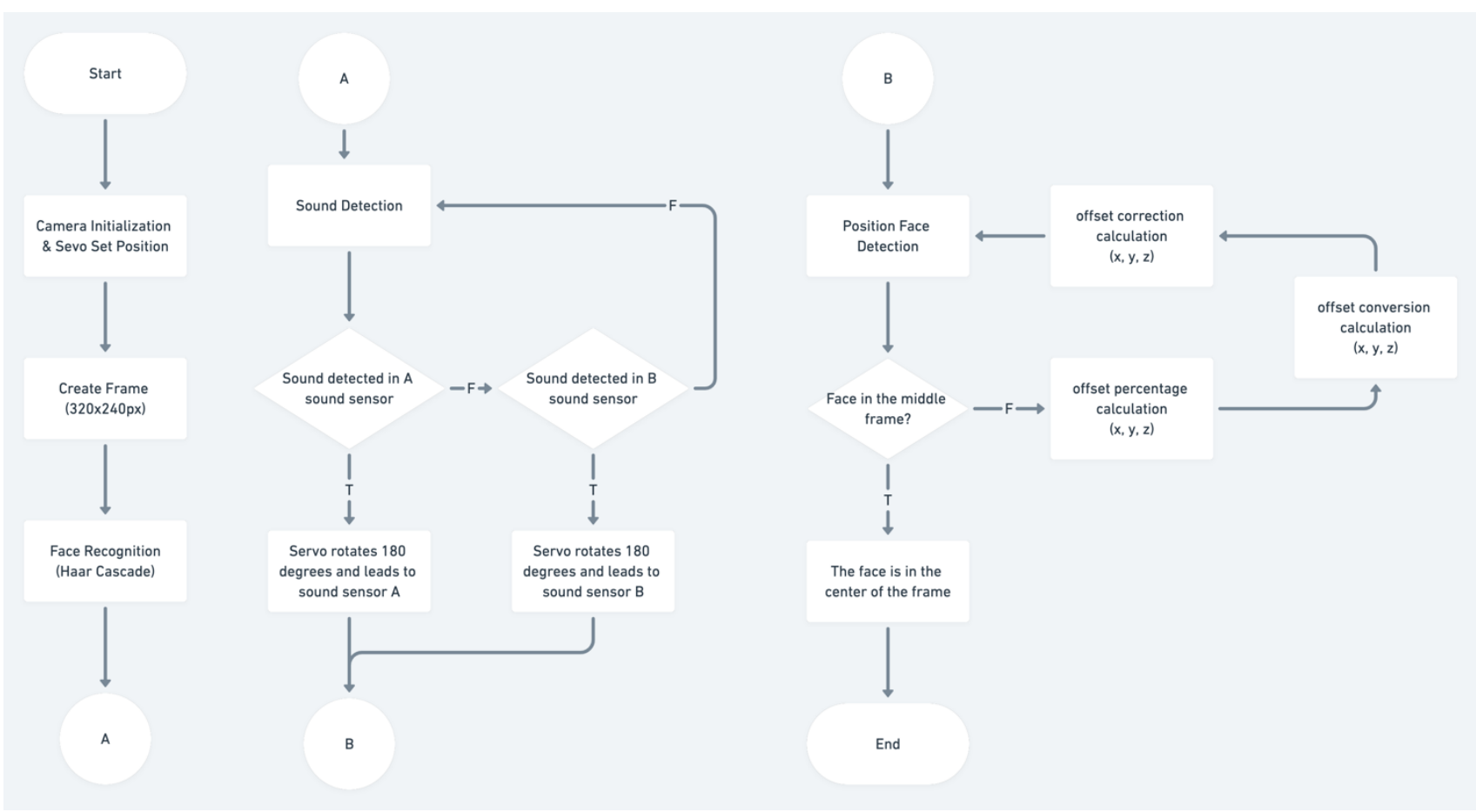

Fig 10: System Flowchart

\subsection{Testing The appearance of a green square on the face}

The Raspberry Pi 4 camera module is utilized to require realtime video. Before the camera module is utilized, it is tried to begin with. Testing is done by running a command made utilizing the python dialect, which is run through the Python IDE. To run it, to begin with, open the organizer that has been named "facetrack.py" at that point, the video show outline that has been made will show up. So that the display will show up as appeared in Figure 11.

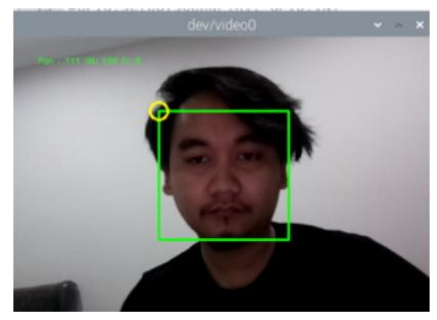

Fig 11: Green Box Output with Face Tracking Sensor.
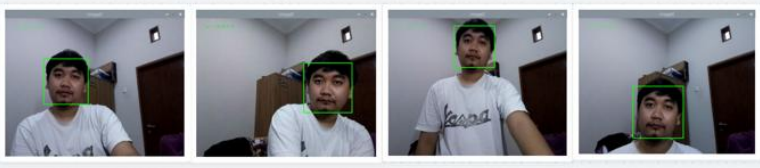

Fig 12: Green Box Output without Face Tracking Sensor.

\subsection{Testing the distance of face tracking sensor based on video resolution}

This test was conducted to discover how distant the following sensor is from video resolutions of $160 \times 128,320 \times 240$, and $640 \times 480$. Face detection is carried out with one user at a separate of 1 meter to 10 meters, and the following results are obtained:
Table 2. Test Results for Face Object Detection Distance with 160x128 Resolution

\begin{tabular}{|c|c|c|}
\hline Testing & Distance(meter) & Status \\
\hline 1 & 1 & Detected \\
\hline 2 & 2 & Not Detected \\
\hline 3 & 3 & Not Detected \\
\hline 4 & 4 & Not Detected \\
\hline 5 & 5 & Not Detected \\
\hline 6 & 6 & Not Detected \\
\hline 7 & 7 & Not Detected \\
\hline 8 & 8 & Not Detected \\
\hline 9 & 9 & Not Detected \\
\hline 10 & 10 & Not Detected \\
\hline
\end{tabular}

Table 3. Test Results for Face Object Detection Distance with 320x240 Resolution

\begin{tabular}{|c|c|c|}
\hline Testing & Distance(meter) & Status \\
\hline 1 & 1 & Detected \\
\hline 2 & 2 & Detected \\
\hline 3 & 3 & Detected \\
\hline 4 & 4 & Detected \\
\hline 5 & 5 & Not Detected \\
\hline 6 & 6 & Not Detected \\
\hline 7 & 7 & Not Detected \\
\hline 8 & 8 & Not Detected \\
\hline
\end{tabular}




\begin{tabular}{|c|c|c|}
\hline Testing & Distance(meter) & Status \\
\hline 9 & 9 & Not Detected \\
\hline 10 & 10 & Not Detected \\
\hline
\end{tabular}

Table 4. Test Results for Face Object Detection Distance with 640x320 Resolution

\begin{tabular}{|c|c|c|}
\hline Testing & Distance(meter) & Status \\
\hline 1 & 1 & Detected \\
\hline 2 & 2 & Detected \\
\hline 3 & 3 & Detected \\
\hline 4 & 4 & Detected \\
\hline 5 & 5 & Detected \\
\hline 6 & 6 & Detected \\
\hline 7 & 7 & Detected \\
\hline 8 & 8 & Detected \\
\hline 9 & 9 & Not Detected \\
\hline 10 & 10 & Not Detected \\
\hline
\end{tabular}

Table 2 separates testing with a determination of $160 \times 128$. Gotten identified status with a separate 1 meter, and other separations were undetected. In Table 3, remove testing with a determination of $320 \times 240$. Gotten with identified status at a remove of 1 meter to 4 meters, and other separations got undetected status. Table 4 separates testing with a determination of $640 \times 480$. Gotten with recognized status at a separate of 1 meter to 8 meters, and other separations got undetected.

\subsection{Response time testing at face tracking}

\section{offset distance}

In this test, we will conduct a test to compare how quick the reaction time is required for confronting the following. This test calculates the delay or slack time between the counterbalanced remove of the $\mathrm{x}$-axis and $\mathrm{y}$-axis until it returns to the center point at the leading determination of $640 \times 480$

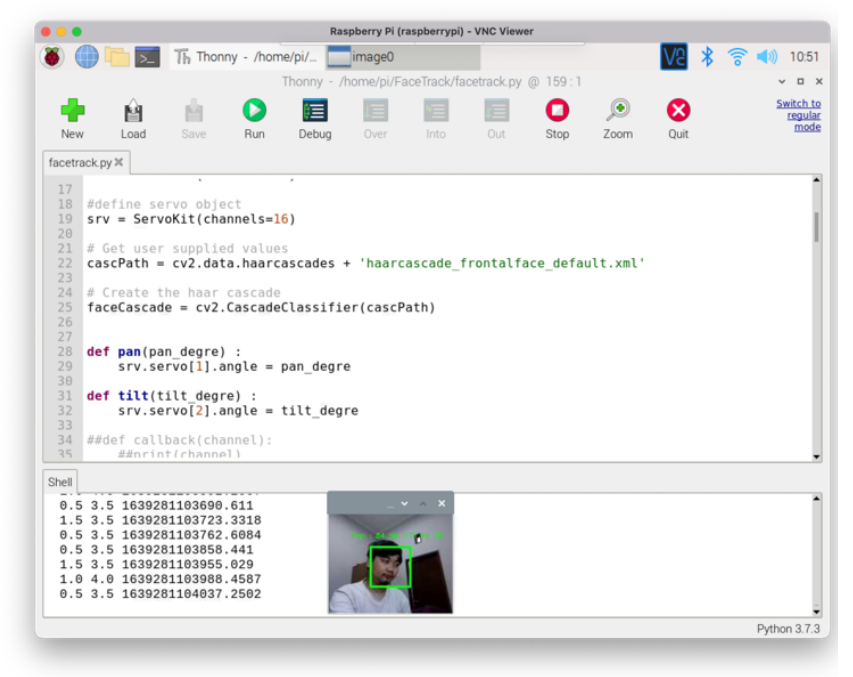

Fig 13: Result of $x, y$-axis value $\&$ epoch time value.

Table 5: $\mathrm{X}$-axis offset time difference test (servo pan).

\begin{tabular}{|c|c|c|c|}
\hline $\begin{array}{c}\text { X-axis } \\
\text { offset(px) }\end{array}$ & $\begin{array}{l}\text { Epoch time } \\
\text { offset (ms) }\end{array}$ & $\begin{array}{l}\text { Epoch time to } \\
\text { center }(\mathrm{ms})\end{array}$ & $\begin{array}{c}\text { Time } \\
\text { diff }(\mathrm{ms})\end{array}$ \\
\hline$>100$ & $\begin{array}{c}163482482946 \\
3,67\end{array}$ & $\begin{array}{c}1634824843246, \\
63\end{array}$ & 13782,96 \\
\hline $80 \mathrm{~s} / \mathrm{d} 99$ & $\begin{array}{c}163482736712 \\
3,41\end{array}$ & $\begin{array}{c}1634827377266 \\
47\end{array}$ & 10143,06 \\
\hline $60 \mathrm{~s} / \mathrm{d} 79$ & $\begin{array}{c}163482484866 \\
2,45\end{array}$ & $\begin{array}{c}1634824860263, \\
15\end{array}$ & 11600,70 \\
\hline $40 \mathrm{~s} / \mathrm{d} 59$ & $\begin{array}{c}163482483560 \\
0,81\end{array}$ & $\begin{array}{c}1634824843784, \\
12\end{array}$ & 8183,31 \\
\hline $20 \mathrm{~s} / \mathrm{d} 39$ & $\begin{array}{c}163482483616 \\
0,23\end{array}$ & $\begin{array}{c}1634824843784, \\
12\end{array}$ & 7623,89 \\
\hline $5 \mathrm{~s} / \mathrm{d} 19$ & $\begin{array}{c}163482722118 \\
4,96\end{array}$ & $\begin{array}{c}\text { 1634827221997, } \\
77\end{array}$ & 812,81 \\
\hline $\begin{array}{c}(-5) \mathrm{s} / \mathrm{d}(- \\
19)\end{array}$ & $\begin{array}{c}163482484270 \\
6,85\end{array}$ & $\begin{array}{c}1634824843246, \\
63\end{array}$ & 539,78 \\
\hline $\begin{array}{c}(-20) \mathrm{s} / \mathrm{d}(- \\
39)\end{array}$ & $\begin{array}{c}163482485785 \\
4,42\end{array}$ & $\begin{array}{c}1634824860263, \\
15\end{array}$ & 2408,73 \\
\hline $\begin{array}{c}(-40) \mathrm{s} / \mathrm{d}(- \\
59)\end{array}$ & $\begin{array}{c}163482738533 \\
0,00\end{array}$ & $\begin{array}{c}1634827392640 \\
89\end{array}$ & 7310,89 \\
\hline $\begin{array}{c}(-60) \mathrm{s} / \mathrm{d}(- \\
79)\end{array}$ & $\begin{array}{c}163482483382 \\
3,54\end{array}$ & $\begin{array}{c}1634824843246, \\
63\end{array}$ & 9423,09 \\
\hline $\begin{array}{c}(-80) \mathrm{s} / \mathrm{d}(- \\
99)\end{array}$ & $\begin{array}{c}163482741683 \\
0,55\end{array}$ & $\begin{array}{c}1634827432563, \\
22\end{array}$ & 15732,67 \\
\hline$<-100$ & $\begin{array}{c}163482740183 \\
3,16\end{array}$ & $\begin{array}{c}1634827424172 \\
92\end{array}$ & 22339,76 \\
\hline
\end{tabular}

Table 5: Y-axis offset time difference test (servo tilt).

\begin{tabular}{|c|c|c|c|}
\hline $\begin{array}{c}\text { Y-axis } \\
\text { offset(px) }\end{array}$ & $\begin{array}{c}\text { Epoch time } \\
\text { offset (ms) }\end{array}$ & $\begin{array}{c}\text { Epoch time to } \\
\text { center }(\mathbf{m s})\end{array}$ & $\begin{array}{c}\text { Timediff } \\
(\mathbf{m s})\end{array}$ \\
\hline$>100$ & $\begin{array}{c}163525809001 \\
0,52\end{array}$ & $\begin{array}{c}1635258092334, \\
31\end{array}$ & 2323,79 \\
\hline $80 \mathrm{~s} / \mathrm{d} 99$ & $\begin{array}{c}163525809022 \\
9,31\end{array}$ & $\begin{array}{c}1635258092334, \\
31\end{array}$ & 2105,00 \\
\hline $60 \mathrm{~s} / \mathrm{d} 79$ & $\begin{array}{c}163525809047 \\
8,55\end{array}$ & $\begin{array}{c}1635258092334, \\
31\end{array}$ & 1855,76 \\
\hline $40 \mathrm{~s} / \mathrm{d} 59$ & $\begin{array}{c}163525809072 \\
8,77\end{array}$ & $\begin{array}{c}1635258092334, \\
31\end{array}$ & 1605,54 \\
\hline $20 \mathrm{~s} / \mathrm{d} 39$ & $\begin{array}{c}163525809099 \\
5,02\end{array}$ & $\begin{array}{c}1635258092334, \\
31\end{array}$ & 1339,29 \\
\hline $5 \mathrm{~s} / \mathrm{d} 19$ & $\begin{array}{c}163525809126 \\
4,24\end{array}$ & $\begin{array}{c}1635258092334, \\
31\end{array}$ & 1070,07 \\
\hline$(-5) \mathrm{s} / \mathrm{d}(-$ & 163525808741 & 1635258089084, & 1673,69 \\
$19)$ & 0,91 & 60 & 1928,94 \\
\hline $\begin{array}{c}(-20) \mathrm{s} / \mathrm{d}(- \\
39)\end{array}$ & $\begin{array}{c}163525808715 \\
5,66\end{array}$ & $\begin{array}{c}1635258089084, \\
60\end{array}$ & \\
\hline
\end{tabular}




\begin{tabular}{|c|c|c|c|}
\hline $\begin{array}{c}(-40) \text { s/d (- } \\
59)\end{array}$ & $\begin{array}{c}163525808687 \\
9,56\end{array}$ & $\begin{array}{c}1635258089084, \\
60\end{array}$ & 2205,04 \\
\hline $\begin{array}{c}\text { Y-axis } \\
\text { offset(px) }\end{array}$ & $\begin{array}{c}\text { Epoch time } \\
\text { offset (ms) }\end{array}$ & $\begin{array}{c}\text { Epoch time to } \\
\text { center (ms) }\end{array}$ & $\begin{array}{c}\text { Time } \\
\text { diff (ms) }\end{array}$ \\
\hline $\begin{array}{c}(-60) \text { s/d (- } \\
79)\end{array}$ & $\begin{array}{c}163525808662 \\
3,47\end{array}$ & $\begin{array}{c}1635258089084, \\
60\end{array}$ & 2461,13 \\
\hline $\begin{array}{c}(-80 \text { s/d (- } \\
99)\end{array}$ & $\begin{array}{c}163525808635 \\
9,53\end{array}$ & $\begin{array}{c}1635258089084, \\
60\end{array}$ & 2725,07 \\
\hline$<-100$ & $\begin{array}{c}163525808610 \\
2,21\end{array}$ & $\begin{array}{c}1635258089084, \\
60\end{array}$ & 2982,39 \\
\hline
\end{tabular}

Within the perception information in Table 5 over, it can be seen that the distinction within the time counterbalanced remove on the $\mathrm{x}$ hub (servo pan) or evenly at a remove more prominent than 100 pixels is $13782 \mathrm{~ms}$, and the littlest counterbalanced remove is gotten at a counterbalanced position of 5 pixels and gets $539 \mathrm{~ms}$. For the observation information in Table 6 , the contrast within the time counterbalanced remove on the y-axis (servo tilt) or vertically at the balanced remove more prominent than 100 pixels is $2323 \mathrm{~ms}$, and the balanced separate from 5 to 19 pixels is $1070 \mathrm{~ms}$.

\subsection{Sound detection test against Camera Movement}

In this test, exploration will be carried out to distinguish two sound sensors on camera development, and the camera will turn 180 degrees concurring to the position of the sound sensor set on both sides of the camera.

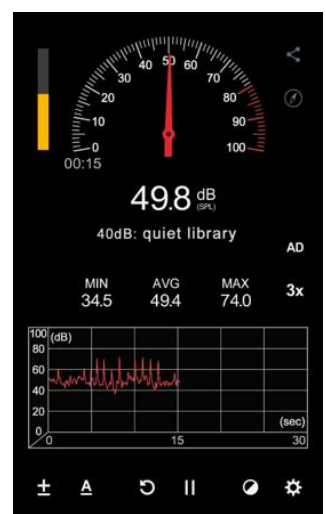

Fig 14: Indoor Clap Test Results

In Figure 14, concentrated sound tests are found in a closed and calm room, where the Clap development is carried out. Furthermore, get the most outstanding result of $74 \mathrm{~dB}$, the minor result of $34.5 \mathrm{~dB}$, and an average decibel within the testing room of $49.4 \mathrm{~dB}$. This test employs a sound sensor with an advanced flag that has set affectability with $74 \mathrm{~dB}$ decibels on both sound sensors, where the sound sensor as it were identifies clapping (clap), and the following results are obtained:
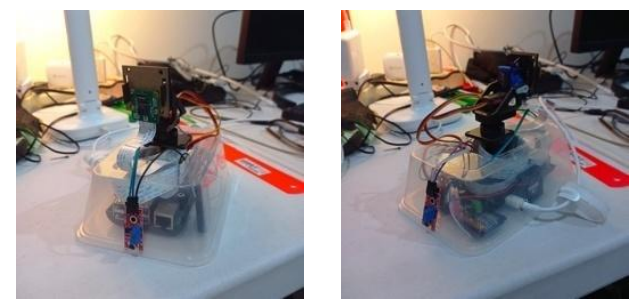

Fig 15: A Side (Sound1) and B Side (Sound2)

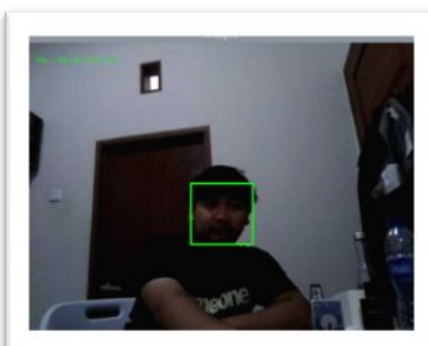

Fig 16: Results of the A-side sound sensor with face tracking (Sound 1).

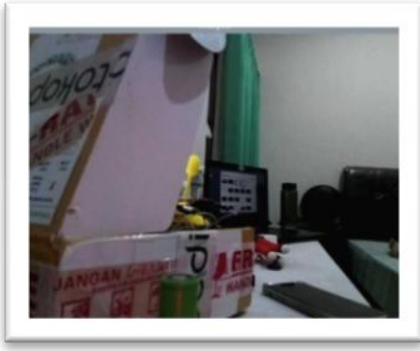

Fig 17: Results of the B-side sound sensor without face tracking (Sound 2).

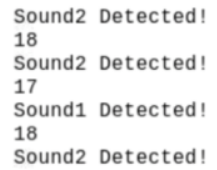

Fig 18: Sound sensor log results detected.

In Figure 15, there are 2pcs KY037 sound sensors set on the front side of the instrument and on the backside of the apparatus, where when the sensor on the front side (Side A) identifies sound, the camera will point 180 degrees to the front side in Figure 16, and vice versa, when the sensor on the backside (Side B) identifies sound, the camera will point 180 degrees to the backside in Figure 17. To discover the sensor location action in this test, the print work is carried out within the python sentence structure produced in Figure 18.

\section{CONCLUSIONS}

Based on the examination, equipment testing, picture handling utilized and conducting a few analysesto make this inquire about, it can be concluded. The plan of a confront following framework with a webcam for an assembly camera based on Raspberry Pi has succeeded in testing the confront following strategy and utilizing the most satisfactory determination utilized agreeing to the Raspberry Pi determinations. Based on inquiring about and testing to discover the leading 
determination within the utilize of confronting following on the Raspberry $\mathrm{Pi}$, three tests were carried out with resolutions of $160 \times 128,320 \times 240$, and $640 \times 480$. At a determination of $640 \times 480$, it produces a more exact confront discovery with a long remove of up to 8 meters and is more steady, while at a determination of $160 \times 128$, it is shorter with the most incredible location separate 1 meter but contains a speedier reaction. Based on research and testing, the finest separate is at a determination of $640 \times 480$, a confront following reaction time is tried against the following counterbalanced separate at the most excellent resolution. The result may be a test of the distinction within the time counterbalanced separate on the $\mathrm{x}$ pivot (servo container) or evenly at a separate more noteworthy than 100 pixels in can be $13782 \mathrm{~ms}$, and the smallest counterbalanced separate is gotten at a counterbalanced position of 5 pixels in $539 \mathrm{~ms}$. For the distinction within the time balanced remove on the y-axis (servo tilt) or vertically at the counterbalanced individual more noteworthy than 100 pixels, $2323 \mathrm{~ms}$ is gotten, and the 5pixel counterbalanced remove $1070 \mathrm{~ms}$. Based on the excellent location test for camera development, there are two sound sensors set on inverse sides (front side and back side), getting suitable comes about where when one of the sound sensors gets a computerized flag reaction, the camera will point to where the sensor is the sound is found, or the servo drive will move the camera 180 degrees.

\section{REFERENCES}

[1] Bo Zhang, Jun Huang and Jinlong Lin, "A Novel Algorithm for Object Tracking by Controlling PAN/TILT Automatically," ICETC: 2nd International Conference on Intelligent System 2010, Vol. VI, pp.596602.

[2] Edavos, "ApaituWebCam", 2021, https://edavos.com/apa-itu-webcam

[3] Fachrur R, "Prototype Alat Pendeteksi Dini Gangguan Fuse Cut Out (FCO) di SistemKelistrikan PLN Menggunakan PZEM-004T, Sensor Suara, dan GPS Berbasis Arduino Mega dengan IoT", Jurnal Teknik Elektro dan Komputasi (ELKOM), 2021.

[4] Gary Bradski and Adrian Kaehler, Learning OpenCV Computer Vision with OpenCV Library, O'REILLY Media, 2008.
[5] Indhu B and VPS Naidu, "Gimballed Camera Control for On-Point Target Tracking," American Research Journal of Electronics and Communication, Vol 1, 2015

[6] Kemdikbud, "PembelajaranTatapMuka", 2021, https://www.kemdikbud.go.id/main/blog/2021/09/suratedaran-penyelenggaraan-pembelajaran-tatap-mukatahun-akademik-20212022

[7] Lienhart, Rainer and Jochen Maydt. "An extended set of haar-like features for rapid object detection." In: IEEE ICIP, Vol.1, pp 900-903 (2002).

[8] Marcelo R, "Real-Time Face Recognition: An End-toEnd Project", 2018, https://www.hackster.io/mjrobot/real-time-facerecognition-an-end-to-end-project-a10826

[9] M. R. SamsulAriefin, C. S. (2014). SISTEM REALTIME UNTUK MANAJEMEN MOBIL ANTARKOTA MENGGUNAKAN NODE JS BERBASIS TCP/IP. Jurnal Coding SistemKomputer Universitas Tanjungpura, 20-30.

[10] P. Viola and M. Jones, "Rapid Object Detection using a Boosted Cascade of Simple Feature," Conference on Computer Vision and Pattern Recognition. IEEE Press, pp. 511-518, 2001

[11] R. Yosafat S, "Design and Implementation of Pan-Tilt Control for Face Tracking," IEEE International Conference on System Engineering and Technology (ICSET 2017), 2 - 3 October 2017

[12] RD. Kusumanto, "RancangBangun Camera Face Tracker DenganMenggunakanMetodeHaar-Like Feature Dan Pid,” JURNAL INTEGRASI Vol. 5, No. 1, 2013

[13] Rinaldy, "Pengendalian Motor Servo Yang TerintegrasiDengan Webcam Berbasis Internet Dan Arduino" JurnalInfotel Vol.5 No.2 November 2013

[14] Tim, "Face and Movement Tracking Pan-Tilt System with Raspberry $\mathrm{Pi}$ and OpenCV" https://coreelectronics.com.au/tutorials/Face-Tracking-RaspberryPi.html

[15] Viola Paul, Jones Michael, "Robust Real-Time Face Detection," International Journal of Computer Vision 57(2), pp. 137-154, 2004 